\title{
Classes sociais e estudantes universitários: Origens, oportunidades e orientações
}

Social classes and university students: origins, opportunities, and orientations Classes sociales et étudiants universitaires : Origines, opportunités et orientations

Fernando Luís Machado, António Firmino da Costa, Rosario Mauritti, Susana da Cruz Martins, José Luís Casanova e João Ferreira de Almeida

\section{OpenEdition} Journals

Edição electrónica

URL: http://journals.openedition.org/rccs/1140

DOI: $10.4000 /$ rccs. 1140

ISSN: 2182-7435

Editora

Centro de Estudos Sociais da Universidade de Coimbra

Edição impressa

Data de publição: 1 Outubro 2003

Paginação: 45-80

ISSN: 0254-1106

\section{Refêrencia eletrónica}

Fernando Luís Machado, António Firmino da Costa, Rosario Mauritti, Susana da Cruz Martins, José Luís Casanova e João Ferreira de Almeida, «Classes sociais e estudantes universitários: Origens, oportunidades e orientações », Revista Crítica de Ciências Sociais [Online], 66 | 2003, colocado online no dia 01 outubro 2012, criado a 30 abril 2019. URL : http://journals.openedition.org/rccs/1140 ; DOI $10.4000 /$ rccs. 1140

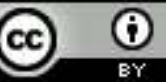




\author{
FERNANDO LUÍS MACHADO \\ ANTÓNIO FIRMINO DA COSTA \\ ROSÁRIO MAURITTI \\ SUSANA DA CRUZ MARTINS \\ JOSÉ LUÍS CASANOVA \\ JOÃO FERREIRA DE ALMEIDA
}

\title{
Classes sociais e estudantes universitários: Origens, oportunidades e orientações
}

\begin{abstract}
A importância da dimensão escolar/educacional na constituição das sociedades actuais e, mais especificamente, na configuração das desigualdades sociais contemporâneas, tem sido um dos principais objectos de interesse da sociologia. Situando-se no quadro desta problemática, o presente artigo analisa, com base nos resultados de um inquérito recente a uma amostra representativa dos estudantes universitários portugueses, as probabilidades desiguais de acesso a esse nível de ensino. A investigação é orientada por um conjunto de propostas teóricas e operatórias para a análise sociológica das classes sociais. São analisadas as relações entre classe de origem e sexo, área de estudos, ensino público/privado e orientações de vida dos estudantes. Estas análises são, por fim, confrontadas com a situação educativa portuguesa no âmbito da União Europeia.
\end{abstract}

\section{Introdução}

As relações entre desigualdades sociais e instituição escolar nas sociedades contemporâneas aparecem como um dos temas centrais da sociologia na segunda metade do século XX. Desde as obras, já clássicas, de Bourdieu (1964, 1970, 1979) ou Boudon (1973), de Coleman (1966) ou Bernstein (1975), entre muitas outras, a análise sociológica procurou investigar a fundo essas relações que surgiam como centralmente estruturantes das sociedades actuais.

As ramificações do tema são múltiplas. A respeito das suas relações com a escola e a escolarização, as desigualdades sociais - de classe, sexo e etnia, nomeadamente - têm sido analisadas dos pontos de vista do acesso (à escola e aos graus de ensino), do processo (de aprendizagem e de interacção na escola) e do sucesso (na trajectória escolar e na aquisição de saberes, competências e credenciais). Na sociologia da educação, depois de oscilações de ênfase, a questão das desigualdades sociais perante a escola parece ter voltado a estar na ordem do dia, e a merecer interesse renovado (Durut-Bellat, 2002; Derouet, 2002). 
Por outro lado, a dimensão escolar/educacional das sociedades actuais tem vindo a ser analisada como uma das mais importantes dimensões constitutivas destas sociedades, com incidência crescente na reconfiguração das desigualdades sociais contemporâneas, quer relativamente às trajectórias de vida individuais, quer no tocante à recomposição das estruturas sociais. Não só os impactos das dimensões escolares/educacionais se vêm revelando cada vez mais fortes, em termos gerais, nas transformações tecnológicas e económicas, cívicas e políticas, comunicacionais e culturais da actualidade, como essas dimensões se inscrevem hoje, de maneira decisiva, na reconfiguração das relações de classe e dos estilos de vida, nos processos de mobilidade social e exclusão social, na formação de disposições pessoais e orientações de vida.

$\mathrm{Na}$ sociologia das classes sociais e da estratificação, a maior parte das propostas teóricas e dos procedimentos operatórios que surgiram desde meados do século XX inclui, na análise das sociedades contemporâneas, algum tipo de especificação das dimensões escolares/educacionais. Para alguns autores de referência nesta área, tais dimensões são tidas em conta, sobretudo, no plano das qualificações e certificações de alcance profissional. É o caso, apesar de todas as diferenças entre os respectivos quadros teóricos, de Nicos Poulantzas (1974) e Erik Olin Wright (1978, 1985, 1997), de Frank Parkin (1979) e de Esping-Andersen (1993). Noutros casos, sem se deixar de considerar o plano socioprofissional, as dimensões em causa são relacionadas, antes de mais, com o plano dos recursos culturais e dos status simbólicos. O exemplo por excelência é, evidentemente, Pierre Bourdieu (1979).

Retomando selectivamente contributos destes autores, e reelaborando abordagens teóricas e operatórias, é possível convocar ambos os aspectos - económico/profissional e cultural/simbólico - para a análise de classes nas sociedades actuais, dando a cada um deles um estatuto analítico específico e combinando-os de maneira elaborada. Podem mencionar-se várias abordagens nesta linha, se bem que bastante diferentes entre si, como, entre outras, as de Klaus Eder (1993), de Michael Vester (2003) ou dos próprios autores deste artigo (Almeida, 1986; Almeida, Costa e Machado, 1994; Machado e Costa, 1998; Costa, 1999; Costa et al., 2000; Machado, 2002). O mesmo pode dizer-se de outros autores portugueses que têm desenvolvido análises convergentes com estas, como Pinto (1985), Pinto e Queiroz (1990), Almeida (1993), Silva (1994), Pereira (1999 e 2002), e outros.

No âmbito geral destas análises, os estudantes universitários revelam-se um objecto de estudo específico, com um interesse sociológico muito espe- 
cial. Eles constituem, com efeito, nas sociedades de hoje, um segmento da população particularmente decisivo pelo seu protagonismo social - quer enquanto jovens estudantes, quer nos seus destinos sociais potenciais e pelo facto de neles se revelarem muitas das dinâmicas de mudança social e cultural mais importantes da actualidade.

Por isso, alguns dos autores deste artigo deram início, desde 1985, no ISCTE, a um programa de investigação sobre os estudantes universitários portugueses, equacionado na perspectiva acima referida, isto é, tomando como ponto focal da análise as origens de classe e as trajectórias de mobilidade social desses estudantes. No conjunto, procurou-se investigar dois conjuntos de atributos - sociais e culturais - e as relações entre eles, o que se traduziu, operatoriamente, num inquérito por questionário com dois grandes blocos de variáveis, relativos, no essencial, a desigualdades sociais e a diferenças culturais. A Figura 1 esquematiza, em termos muito gerais, o modelo de análise utilizado.

De acordo com este modelo analítico, ${ }^{1}$ as variáveis de caracterização de classe podem ser tomadas como indicadores, tanto das distribuições relacionais de posições sociais (espaço social das classes) como das inserções e trajectos de cada indivíduo, ou conjunto de indivíduos, no espaço das relações de classe (biografias de classe). $\mathrm{E}$ as variáveis referentes a valores culturais e representações simbólicas são utilizáveis como indicadores quer de sistemas simbólico-ideológicos que se vão formando e transformando a nível societal (configurações culturais), quer dos sistemas cognitivos e

\section{FIGURA 1 - Modelo para a análise de classes}

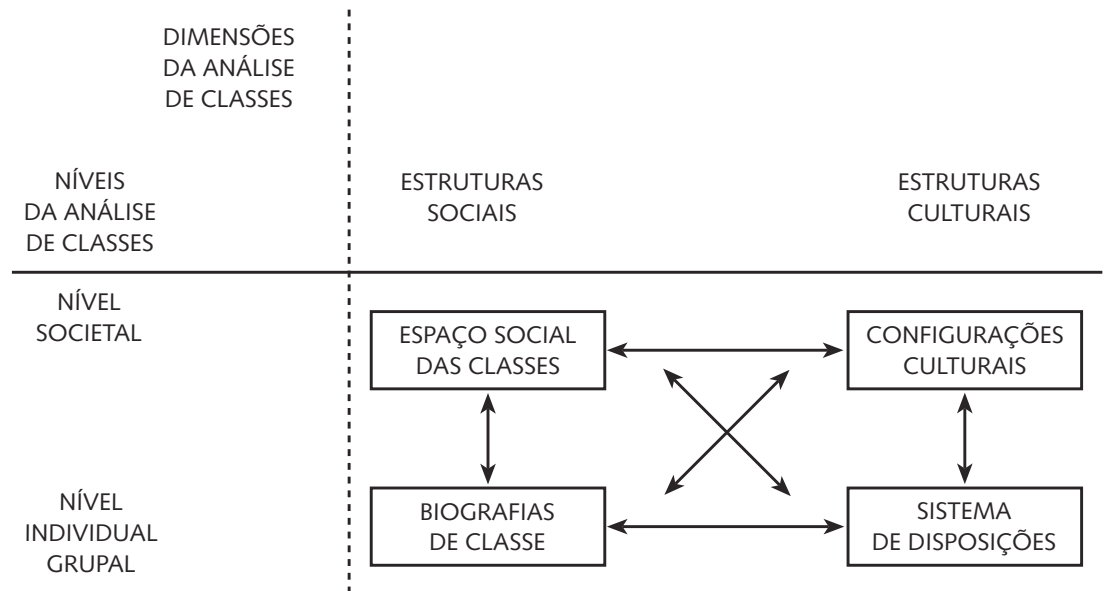

${ }^{1}$ Retoma-se aqui o modelo de análise apresentado em Costa, Machado e Almeida (1990). 
valorativos que indivíduos e grupos vão interiorizando e accionando, de modo mais implícito ou mais reflexivo, na prática social (sistemas de disposições).

Falta neste modelo, claro está, a consideração específica do nível meso-social, relativo aos diversos quadros de interacção em que se processa contextualmente a prática social, sejam esses quadros de interacção configurados de forma institucional, organizacional ou local, envolvam grupos ou redes sociais, ou, mais provavelmente, convoquem combinações diversas destes e doutros elementos. ${ }^{2} \mathrm{O}$ inquérito aplicado inclui um número considerável de questões que permitem tomar em conta alguns parâmetros desta ordem, por exemplo as que se referem aos cursos frequentados, ou às regiões do país, ou às redes de parentesco e amizade. Mas o desenho da pesquisa situa-a de forma predominante nas articulações de conjunto entre os níveis societal e individual.

Os primeiros resultados do programa de investigação referido encontram-se em três publicações iniciais (Almeida, Costa e Machado, 1988; Machado, Costa e Almeida, 1989; Costa, Machado e Almeida, 1990) e uma um pouco posterior (Casanova, 1993), apoiadas, na altura, na aplicação do inquérito apenas a alguns cursos superiores. As análises nelas então desenvolvidas situavam-se, de algum modo, na sequência de alguns outros estudos desenvolvidos na sociologia portuguesa desde a década de 60/70, nomeadamente por Adérito Sedas Nunes (2000a e 2000b), onde era já central a questão da origem social dos estudantes universitários, e precediam todo um outro conjunto de trabalhos sobre os jovens em geral, e os estudantes do ensino superior, em particular. ${ }^{3}$

Em 1999, foi possível a uma equipa do CIES/ISCTE, em colaboração com o Observatório Permanente da Juventude, sediado no Instituto de Ciências Sociais da Universidade de Lisboa, com apoio da Secretaria de

\footnotetext{
${ }^{2}$ Esse nível meso-social tem sido, porém, nomeadamente no domínio das análises de classes sociais, e quando o tipo de investigação em causa o requer, objecto de tratamento analítico aprofundado por parte dos autores deste artigo - Almeida (1986), Costa (1999), Machado (2002) - sempre em articulação com os níveis explicitados no modelo da Figura 1, os quais são, em geral, os que presidem aos objectivos analíticos dos inquéritos extensivos.

${ }^{3}$ Para além das publicações do Programa de Investigação sobre os Estudantes Universitários do CIES/ISCTE (as anteriores, já referidas no texto, e as mais recentes, mencionadas na nota 4), em que o presente artigo se insere, esse conjunto de outros estudos inclui trabalhos como os de Figueiredo (1988), Pais (1993), Cruz et al. (1995a e b), Almeida et al. (1996), Lopes (1997), Fernandes et al. (1998), Pais et al. (1998), Cabral et al. (1998), Figueiredo, Silva e Ferreira (1999), Balsa et al. (2001), Figueiredo (2001), Gonçalves, Parente e Veloso (2001), Alves (2001), Fernandes (2001), Estanque e Nunes (2002). De referir também alguns estudos comparativos internacionais que incluem referências aos jovens portugueses, como os de Smithson, Lewis e Guerreiro (1998), Lewis et al. (1999) ou Pais (1999).
} 
Estado da Juventude, aplicar o mesmo questionário através de inquérito a uma amostra representativa nacional (Continente) de 2000 estudantes de licenciatura do ensino universitário, estratificada por áreas de estudos, subsistemas de ensino universitário (público, privado) e regiões. No presente artigo apresentam-se alguns dos principais resultados desta nova aplicação do inquérito. ${ }^{4}$

Tendo de escolher de maneira muito selectiva os resultados a apresentar neste artigo, concentramo-nos aqui em duas questões analíticas: a) a das desigualdades sociais no acesso ao ensino universitário; b) a das orientações de vida desses estudantes.

\section{Da teoria à operacionalização na análise de classes: algumas questões}

Com a primeira questão pretende-se basicamente averiguar o seguinte: até que ponto as oportunidades sociais de acesso ao ensino universitário português actual são, ainda, condicionadas por factores que, a atender aos valores culturais socialmente prevalecentes e que presidem às orientações institucionalmente explicitadas para o sistema de ensino, não deveriam afectar de maneira significativa esse acesso? Em concreto, haverá, ainda, desigualdades importantes no recrutamento social dos estudantes consoante as suas diferentes origens sociais?

Os aspectos sociologicamente relevantes envolvidos na análise desta questão são muito numerosos e complexos. Mas, no seu núcleo, está a análise das origens de classe dos estudantes, efectuada nesta abordagem analítica através da utilização de indicadores socioprofissionais e indicadores socioeducacionais, dois tipos de indicadores que, criteriosamente construídos, são fundamentais nas análises de classes (Costa, 1999: 189-288, e Costa et al., 2000).

Se os indicadores socioeducacionais, devido à forte institucionalização estatal dos sistemas de graus de ensino, têm formas de operacionalização simples (embora os graus de ensino oficiais constituam, eles próprios, sistemas de classificações sociais muito menos transparentes do que possa parecer à primeira vista, relativamente aos processos de construção social que lhes estão subjacentes e que deles resultam), ${ }^{5}$ os indicadores socioprofissionais implicam elaboração específica mais elaborada. Dependem, designadamente, de um conjunto interligado de opções teóricas e operatórias sofisticadas, de que se têm ocupado os especialistas na área.

\footnotetext{
${ }^{4}$ Dele decorreram já, também, um livro (Almeida et al., no prelo), uma tese de mestrado e um outro artigo (Mauritti, 2000 e 2002).

5 A respeito dos graus de ensino institucionalizados como sistemas de classificações sociais, ver Costa (1998).
} 
Não sendo ocasião de desenvolver aprofundadamente o assunto, importa referir que as principais soluções praticadas na sociologia portuguesa (e em boa parte da sociologia internacional) retomam directamente quatro alternativas, ou inspiram-se nelas: nas categorias socioprofissionais francesas (Desrosières e Thévenot, 1988); nos esquemas de classes profissionais de John H. Goldthorpe (1980) e Erikson e Goldthorpe (1993); nas tipologias de lugares de classe de Erik Olin Wright (1978, 1985, 1997); e nos sistemas de indicadores socioprofissionais de classe desenvolvidos pelos autores deste artigo nos trabalhos já atrás referidos.

Os fundamentos teóricos, os procedimentos operatórios e as vantagens analíticas desta última opção têm sido objecto de explicitação nesses trabalhos, nomeadamente em alguns dos mais recentes (Costa, 1999; Costa et al., 2000), pelo que pode aqui dispensar-se em grande parte a sua apresentação. Mas é importante, pelo menos, apresentar duas matrizes: uma com o algoritmo de construção das categorias individuais de classe, a partir dos indicadores "profissão" e "situação na profissão" (Figura 2); outra com o algoritmo de construção das categorias de classe para os grupos domésticos (Figura 3).

Por outro lado, ainda neste registo muito sintético, e atendendo a que a tipologia de Wright (tipologia W) tem sido usada entre nós por alguns investigadores, como Estanque e Mendes (1997) e Estanque (2000), convém mencionar algumas das razões que nos levam a preferir a que nós próprios elaborámos. Não estão em causa os muitos méritos conceptuais e operatórios das propostas de Wright. Mas têm também problemas que podem ser superados pela tipologia ACM (Almeida, Costa e Machado).

Vários desses problemas respeitam a insuficiências quanto às dimensões de análise e respectivas consequências nas categorias classificatórias da tipologia W. Para ir directamente a estas últimas, é fácil verificar que essa tipologia de lugares de classe é excessivamente desagregada nas "classes médias" e excessivamente agregada nas "classes populares".

Se o excesso de desagregação é sempre analiticamente ultrapassável, através de operações de agregação a posteriori, o excesso de agregação é irrecuperável. Três das categorias utilizadas na tipologia ACM, os empregados executantes (EE), os operários industriais $(\mathrm{OI})$ e os assalariados agrícolas (AA), ficam indestrinçavelmente englobadas na categoria dos proletários da tipologia W. Ora a distinção estrutural entre aquelas três categorias tem alicerces teóricos sólidos e pertinência substantiva incontornável nas sociedades actuais. Basta atender a aspectos como os diferentes contextos e conteúdos de trabalho, as tendências muito diversas (ou mesmo de sentidos opostos) de crescimento ou decréscimo das respectivas impor- 
tância quantitativa e recomposição qualitativa, remetendo para dinâmicas de fundo actuais de reestruturação económica, social e cultural, ou, ainda, para os contrastes de composição sexual dessas categorias de lugares de classe.

Isto é, por um lado, no plano substantivo, a tipologia W, apesar de conter um número de categorias bastante grande (12), não consegue captar nem permite analisar diferenças estruturais decisivas na composição e

FIGURA 2 - Matriz de construção do indicador individual de classe

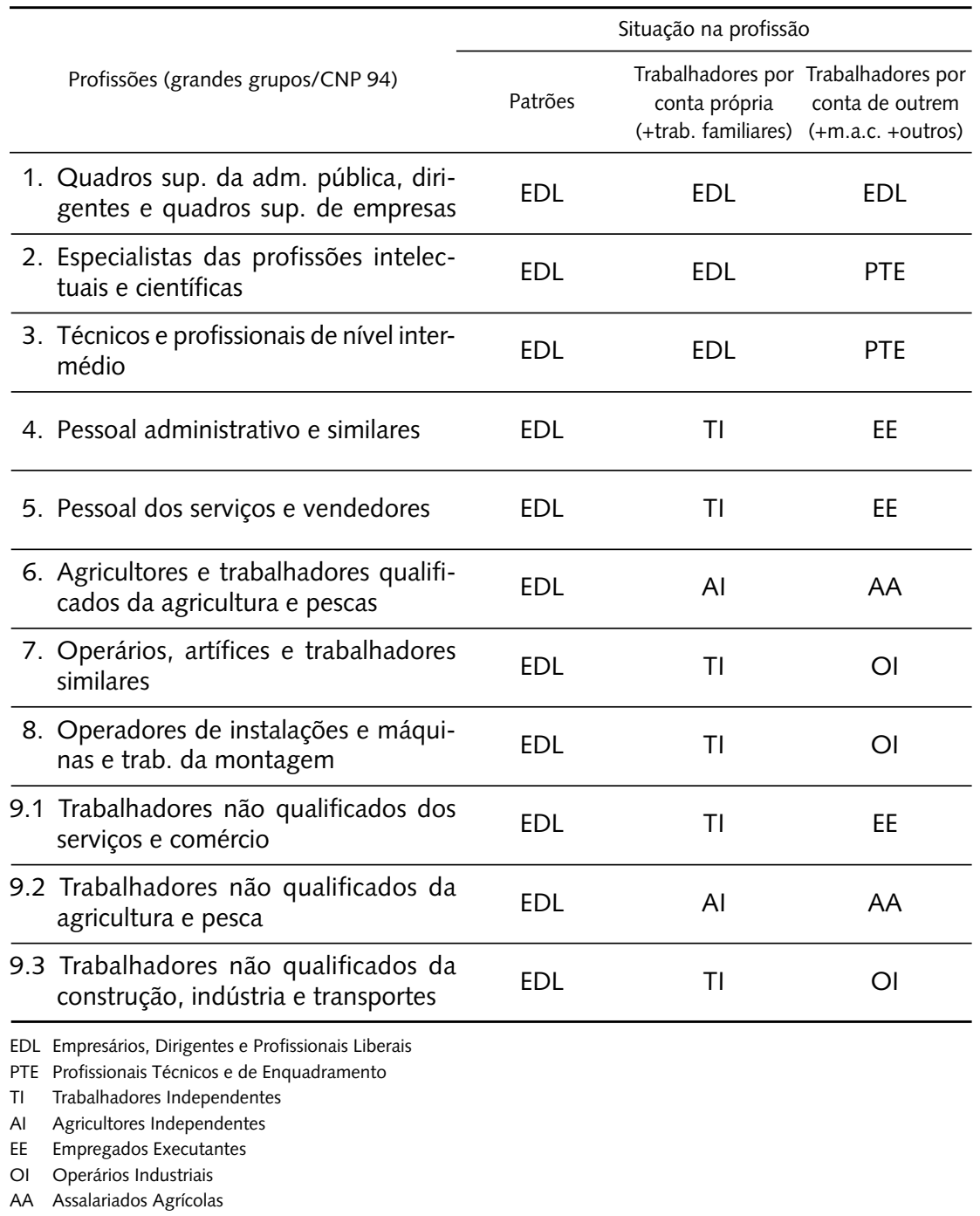


FIGURA 3 - Matriz de construção do indicador familiar de classe

\begin{tabular}{|c|c|c|c|c|c|c|c|c|}
\hline \multicolumn{2}{|c|}{ Mulher } & \multicolumn{7}{|c|}{ Homem } \\
\hline & EDL & PTE & $\mathrm{TI}$ & $\mathrm{Al}$ & $\mathrm{EE}$ & OI & $A A$ & \\
\hline & EDL & EDL & EDL & EDL & EDL & EDL & EDL & EDL \\
\hline & PTE & EDL & PTE & PTE & PTE & PTE & PTE & PTE \\
\hline & $\mathrm{TI}$ & EDL & PTE & TI & TIpl & TIpl & TIpl & TIpl \\
\hline & $\mathrm{Al}$ & EDL & PTE & TIpl & $\mathrm{Al}$ & Alpl & Alpl & Alpl \\
\hline & $\mathrm{EE}$ & EDL & PTE & TIpl & Alpl & $\mathrm{EE}$ & AEpl & AEpl \\
\hline & Ol & EDL & PTE & TIpl & Alpl & AEpl & Ol & AEpl \\
\hline & $A A$ & EDL & PTE & TIpl & Alpl & AEpl & AEpl & AA \\
\hline \multicolumn{9}{|c|}{ EDL Empresários, Dirigentes e Profissionais Liberais } \\
\hline PTE & \multicolumn{8}{|c|}{ Profissionais Técnicos e de Enquadramento } \\
\hline $\mathrm{TI}$ & \multicolumn{8}{|c|}{ Trabalhadores Independentes } \\
\hline TIpl & \multicolumn{8}{|c|}{ Trabalhadores Independentes Pluriactivos } \\
\hline $\mathrm{Al}$ & \multicolumn{8}{|c|}{ Agricultores Independentes } \\
\hline Alpl & \multicolumn{8}{|c|}{ Agricultores Independentes Pluriactivos } \\
\hline $\mathrm{EE}$ & \multicolumn{8}{|c|}{ Empregados Executantes } \\
\hline Ol & \multicolumn{8}{|c|}{ Operários Industriais } \\
\hline AA & \multicolumn{8}{|c|}{ Assalariados Agricolas } \\
\hline AEpl & \multicolumn{8}{|c|}{ Assalariados Executantes Pluriactivos } \\
\hline
\end{tabular}

recomposição de classe das sociedades actuais. Por outro lado, no plano técnico, conduz a distribuições estatísticas muito desequilibradas, tipicamente com cerca de $50 \%$ das populações nacionais numa única categoria (os proletários) e os restantes distribuídos pelas outras onze categorias, o que prejudica o tratamento estatístico das relações entre variáveis, através do qual se operacionaliza com frequência a análise de classes a nível de grandes conjuntos sociais, nível para o qual estas categorizações são principalmente concebidas.

A tipologia ACM, sendo mais compacta, o que é vantajoso na análise estatística, dá conta, de maneira mais abrangente, das principais clivagens e articulações estruturais entre dimensões de análise de classes, permitindo ainda realizar, com coerência conceptual e com facilidade de procedimentos, operações de agregação ou desagregação classificatória, consoante os objectos e níveis de análise específicos.

Além disso, prevê versões complementares para a unidade de análise "indivíduo" e para a unidade de análise "grupo doméstico" (ou, segundo a mesma lógica, para situações de pluriactividade individual), como pode ver-se nas figuras 2 e 3 . Sublinhe-se que em nenhuma dessas versões se 
incorre nos conhecidos problemas do critério "convencional" para a classificação dos indivíduos ou famílias, critério com raízes em trabalhos teóricos como os de Parsons e em propostas operatórias como as de Goldthorpe, nas quais as mulheres são classificadas de acordo com as categorias socioprofissionais dos homens (maridos ou pais). Pelo contrário, na tipologia ACM para grupos domésticos utiliza-se, de acordo com a ponderação de razões de pertinência teórica e de adequabilidade substantiva, o critério da "dominância" ou o da "conjugação" (neste, com criação de novas categorias), em qualquer caso integrando na classificação, sem hierarquia apriorística, ambos os sexos. ${ }^{6}$

A questão da unidade de análise liga-se a outro dos problemas de que sofre a abordagem teórico-operatória de Wright, relativo à mobilidade social intergeracional. Mais especificamente, o problema está sobretudo no modo como analisa as origens de classe. Toda a análise de Wright se centra nos contextos profissionais individuais (ou, como diz o autor, no "ponto da produção"). Não só a tipologia W dos lugares de classe é conceptualizada nesses termos, como as extensões que Wright faz das análises de classes, de modo a tratar temas como a mobilidade intergeracional, as redes de amizade e as famílias envolvendo indivíduos com diversos lugares de classe, procedem do mesmo modo (Wright, 1997).

Se tal opção parece pertinente para diversos objectos de estudo (por exemplo, para analisar eventuais associações tendenciais entre lugares de classe e atitudes perante as relações de trabalho), embora porventura redutora, já para outros não se vislumbra essa pertinência. O próprio Erik Olin Wright avança que, se para analisar "interesses" a localização de classe actual do indivíduo pode ser altamente explicativa, já para analisar "identidades" as origens de classe poderão ser mais relevantes. Mas, independentemente de esta asserção substantiva se revelar ou não bem alicerçada (ela é, obviamente, discutível), o facto é que, mesmo neste caso, Wright se limita a analisar as origens de classe exclusivamente de acordo com a inserção dos pais no contexto profissional.

Ora, para analisar questões como a das influências das origens de classe diferenciais nas trajectórias de escolarização dos filhos, ou, no caso concreto aqui em estudo, as probabilidades desiguais de acesso ao ensino universitário, não será fundamental tomar em consideração os grupos domésticos de origem enquanto contextos de mobilização de recursos partilhados e de processos de socialização construídos em comum? Não requer isto um modo mais integrador de contemplar, na construção das variáveis explicativas, os

\footnotetext{
${ }^{6}$ Explicações mais desenvolvidas a este propósito encontram-se em Costa (1999: 235-245).
} 
vários membros do grupo doméstico, ou pelo menos os seus elementos conjugais nucleares? Não torna isto também as inserções profissionais dos pais um indicador indirecto e insuficiente? Não será decisivo, para análises como esta, tomar em conta outras dimensões de localização das famílias de origem no espaço social das classes, enquanto espaço relacional estruturado por distribuições desiguais de recursos de diversa ordem, designadamente económicos, culturais e relacionais, para fazer apelo a propostas como as de Pierre Bourdieu?

Poderia anotar-se, de passagem, que, se em Wright falta uma consideração mais de fundo da unidade de análise familiar e das dimensões de assimetria social não directamente profissionais (nomeadamente da ordem dos recursos escolares, das disposições culturais, das redes sociais, dos estilos de vida ou dos status simbólicos), em Bourdieu falta uma especificação mais elaborada das assimetrias sociais que se estruturam em contexto profissional, algo para que Wright dá contributos importantes.

As tipologias ACM, com a sua multidimensionalidade constitutiva, com a utilização complementar sistemática de indicadores socioprofissionais e socioeducacionais, e com a combinação de unidades de análise individuais e familiares, dão algumas respostas, ainda que, evidentemente, parcelares, aos problemas referidos.

Nas análises que se seguem, recorre-se a uma tipologia de classe dos grupos domésticos de origem como variável fundamental, a par de uma tipologia de recursos educacionais desses grupos domésticos construída segundo um critério de dominância (grau de ensino mais elevado de pai ou mãe), isto é, de novo, sem hierarquia apriorística baseada no sexo. Também neste aspecto, tal como no dos indicadores socioprofissionais, se trata de uma opção teórico-operatória ajustada às tendências substantivas de fundo que caracterizam as sociedades actuais.

A análise das probabilidades diferenciais de acesso ao ensino universitário obrigou, no entanto, a comparar dados relativos a origens de classe dos familiares dos estudantes inquiridos com dados de caracterização censitária da população portuguesa produzidos pelo Instituto Nacional de Estatística (INE), os quais só existem segundo unidades de análise individuais.

Assim, nos cálculos específicos dos indices de recrutamento de classe (Quadro 1), uma vez que não era possível a comparação directa entre dados construídos segundo unidades de análise diferentes, foi necessário realizar estimativas. Optou-se por duas, cada uma com o seu tipo de aproximação: numa, agregaram-se as origens de classe familiares em apenas cinco categorias, sendo que nos casos de combinatórias familiares de empregados exe- 
Classes sociais e estudantes universitários | 55

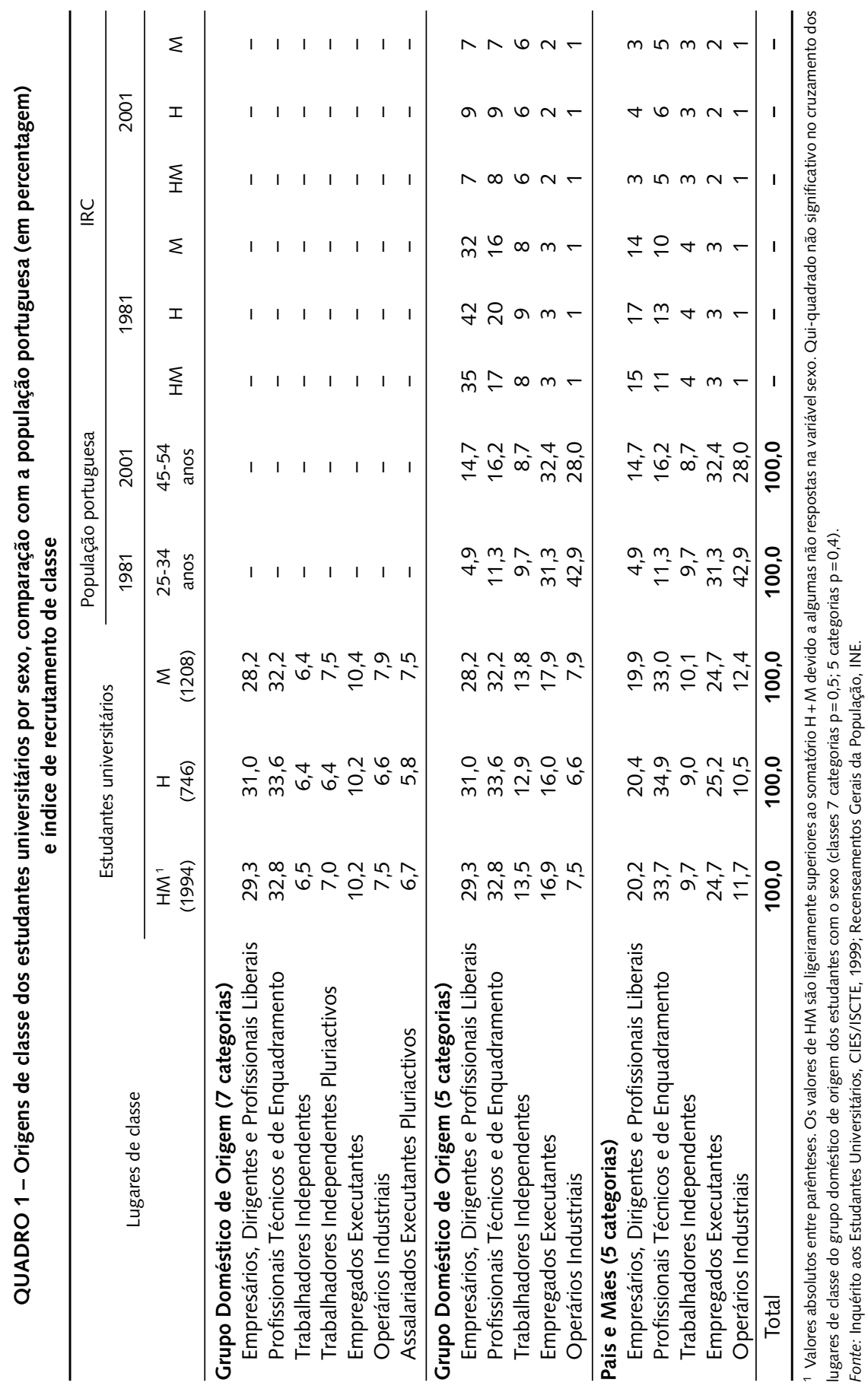


cutantes e operários industriais, e apenas nestes casos, se recorreu ao critério dito "convencional"; noutra, com as mesmas cinco categorias, utilizou-se a unidade de análise individual, reportando-se assim os dados ao conjunto de indivíduos pais e mães. A interpretação pode ainda ser controlada através do confronto com os dados relativos às distribuições pelos lugares de classe construídos segundo a tipologia ACM para grupos domésticos. Procedeu-se de maneira semelhante para a construção dos índices de recrutamento escolar (Quadro 2).

Os índices de recrutamento calculados permitem visualizar com clareza e simplicidade as probabilidades diferenciais de acesso ao ensino superior, consoante a origem social. O estabelecimento de várias estimativas, balizadas pela utilização de diversas unidades de análise e diversas datas de referência pertinentes, possibilita, apesar das limitações dos dados oficiais de caracterização censitária da população, análises controladas e elucidativas.

Como se disse, a análise das desigualdades sociais no acesso ao ensino universitário é o objecto principal deste trabalho. No caso vertente, privilegiou-se a investigação das desigualdades de classe, em si mesmas e, também, nas suas articulações com as desigualdades de assentes na diferença sexual, articulações cada vez mais alvo de tratamento teórico e investigação empírica (Crompton, 2003).

Por um lado, como se tem vindo a referir, essas articulações estão inscritas em profundidade na análise empreendida, não apenas no relativo à conceptualização teórica geral, mas também, em concreto, nas soluções operatórias elaboradas, nomeadamente quanto a unidades de análise, critérios classificatórios e tipologias de classe.

Por outro lado, e não menos importante, examinam-se sistematicamente os resultados segundo o sexo dos estudantes. As interrogações a que se procurou responder são, deste ponto de vista, as seguintes: quanto ao acesso ao ensino superior, em geral, ou quanto à presença efectiva em cada uma das diversas áreas de conhecimento, em particular, as probabilidades revelam-se iguais ou desiguais para homens e mulheres? Ou, dizendo de outro modo, em que medida as desigualdades de classe na universidade são moduladas segundo o sexo?

\section{Padrões de recrutamento social e probabilidades desiguais de acesso}

Uma análise global do Quadro 1 mostra a clara predominância dos sectores de classe mais dotados de capitais económicos, culturais, escolares e sociais, ou seja, as famílias de empresários, dirigentes e profissionais liberais, por um lado, e de profissionais técnicos e de enquadramento, por outro. Em conjunto, $62 \%$ dos estudantes universitários provêm dessas duas catego- 
Classes sociais e estudantes universitários | 57

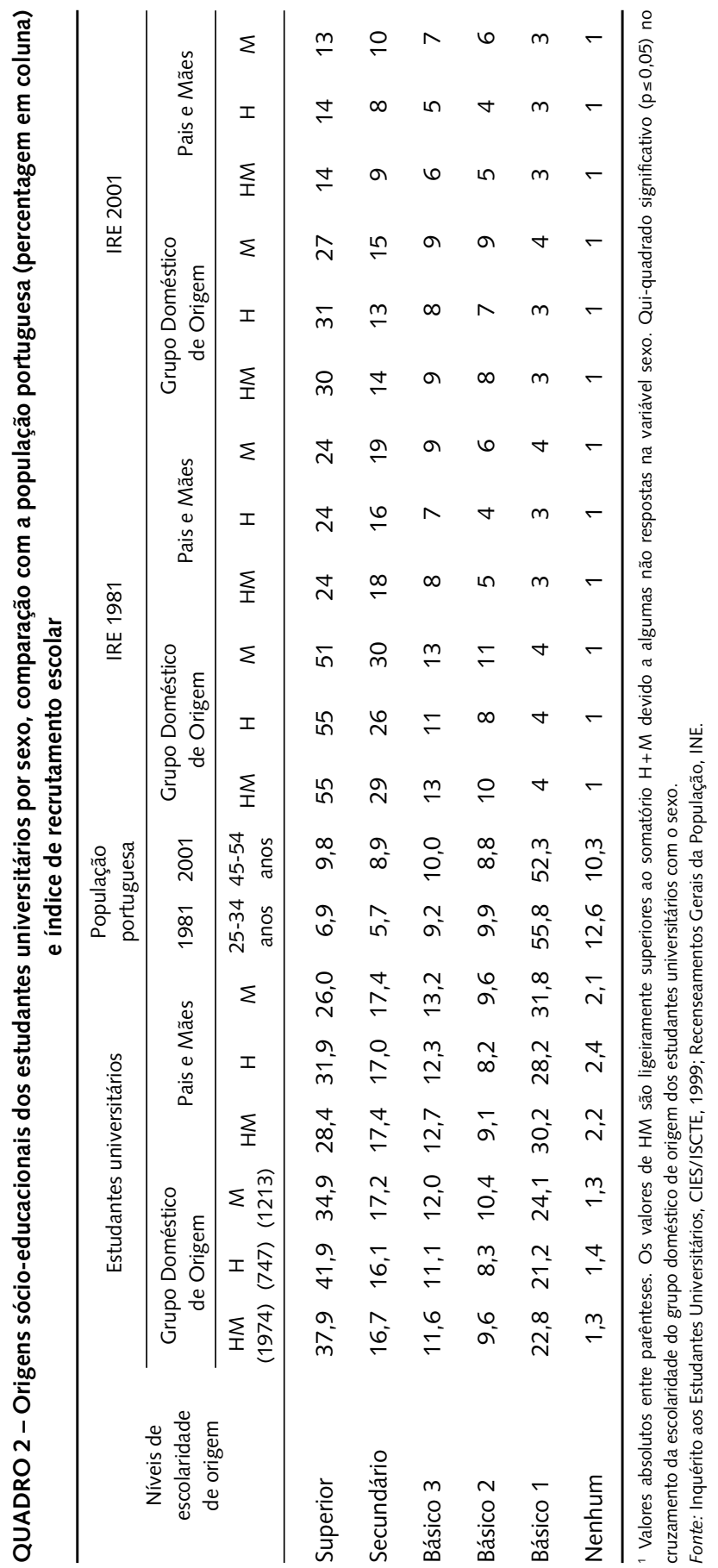


rias de classe. Paralelamente, regista-se uma presença significativa de estudantes oriundos de meios sociais menos providos de qualquer desses tipos de recursos.

Há, pois, um duplo padrão de recrutamento de classe, o que significa que na universidade se repercutem e jogam dinâmicas de reprodução, mas também de mobilidade social, seja essa mobilidade total, seja sob a forma de trajectórias estacionárias com promoção escolar, que é a dos estudantes procedentes de famílias de profissionais técnicos e de enquadramento e, sobretudo, de empresários e dirigentes, com níveis de escolaridade baixos ou médios (Costa, Machado e Almeida, 1990).

Esse duplo padrão de recrutamento classista é, sem dúvida, consequência da progressiva abertura social do sistema universitário, iniciada a seguir a Abril de 74 e que conheceu uma grande expansão nos anos 90. Nessa medida, a análise da composição de classe dos estudantes universitários é reveladora de dinâmicas de recomposição política, económica, social e cultural que caracterizam Portugal nas últimas décadas. É essa democratização do acesso que permite que sectores de classe fracamente dotados de qualificações escolares, aspecto em que, apesar da recuperação verificada, o país continua a uma distância considerável de todos os membros da União Europeia (Costa et al., 2000), coloquem, apesar disso, muitos dos seus descendentes na universidade.

Analisando mais de perto as origens de classe dos estudantes, vê-se que, de entre os sectores sociais menos providos de recursos, são os filhos de empregados executantes os que mais chegam à universidade. Mais do que os filhos de operários e também mais do que os filhos de trabalhadores independentes. Não se trata de uma distribuição destituída de significado sociológico. O melhor posicionamento das famílias de empregados executantes, no que toca à possibilidade de fazer chegar os seus filhos ao ensino universitário, pode explicar-se pelas suas vantagens relativas quanto ao capital cultural, regra geral maior do que nas famílias operárias e de trabalhadores independentes, e dos efeitos desse capital no que toca às condições de aquisição de capital escolar no sistema de ensino. A menor distância relativa dos grupos domésticos de empregados executantes ao sistema universitário é ainda mais visível quando se adopta a tipologia mais fina de sete categorias de classe. Entre as cinco categorias globalmente menos providas de recursos, as famílias de empregados executantes são as que surgem em melhor posição.

Aqui se encontra um dos muitos exemplos possíveis em que a acuidade analítica destas tipologias de classe face às de outros autores, nomeadamente a de Wright (1997), se torna bastante evidente. Como se disse atrás, 
ao agregar numa só categoria todos os assalariados de base, os aqui designados empregados executantes, operários industriais e assalariados executantes pluriactivos, Wright perde de vista as linhas que diferenciam essas categorias umas das outras, aos mais diversos níveis.

Uma leitura complementar das origens de classe dos estudantes é a que pode ser obtida considerando não os lugares de classe das suas famílias de origem, mas os lugares de classe dos seus pais e mães individual e separadamente considerados. Trata-se, portanto, de olhar o mesmo conjunto de trajectos intergeracionais recorrendo a duas unidades de análise diferentes, o grupo doméstico ou o indivíduo. Essas unidades de análise têm sido discutidas, nas suas virtualidades e limites, e aplicadas, sem escolhas unilaterais pré-determinadas, segundo critérios de complementaridade, em numerosos estudos sobre classes em Portugal, de há vinte anos a esta parte (Almeida, 1986; Almeida, Costa e Machado, 1988; Machado, Costa e Almeida, 1989; Costa, Machado e Almeida, 1990; Casanova, 1993; Costa, 1999; Machado, 2002; Mauritti, 2002).

$\mathrm{Na}$ óptica da unidade de análise individual, verifica-se que o perfil de classe dos estudantes, quanto à origem, aparece puxado "para baixo" por comparação com o que resulta da utilização da unidade de análise familiar. Os sectores de classe mais favorecidos, pelo menos no plano económico, aparecem com menor peso relativo; os empregados executantes e os operários registam valores substancialmente mais altos.

A diferença entre as duas distribuições, familiar e individual, resulta do facto de no primeiro caso se ter optado por atribuir aos núcleos conjugais o lugar de classe do elemento mais dotado de recursos, independentemente do sexo. Como muitos núcleos conjugais agregam homens e mulheres com lugares de classe individuais desiguais, o efeito resultante da aplicação desse critério de dominância de recursos é o de um "nivelamento por cima" das localizações de classe das famílias.

A utilização da unidade de análise individual, gera, portanto, neste caso, a ilusão de que o padrão de recrutamento de classe dos estudantes universitários é mais aberto do que realmente é. Uma parte considerável dos estudantes com pais ou mães trabalhadores independentes, empregados executantes ou operários chegará à universidade justamente porque a outra figura parental tem uma localização de classe individual mais vantajosa, o que se repercute positivamente na economia material e simbólica dos respectivos grupos domésticos, seja pelo lado dos recursos, seja pelo lado da socialização familiar. Para o perceber, basta ver como estão sub-representados os estudantes universitários de famílias de empregados executantes, de trabalhadores independentes e, sobretudo, de operários. 
Se a distribuição das origens de classe dos estudantes, só por si, já deixa antever que o seu recrutamento se processa de forma muito desigual nos diferentes sectores da estrutura social, a medição mais rigorosa da amplitude dessa desigualdade de acesso é fornecida pelo cálculo de índices de recrutamento de classe, que comparam o perfil de classe das famílias a que eles pertencem com o perfil de classe do conjunto das famílias portuguesas em tempos de referência pertinentes.

Trata-se de uma forma de medir a mobilidade social que não se limita a confrontar uma dada condição social no momento de observação (a condição de estudante universitário) com uma dada condição de origem (lugar de classe da família), mas que inscreve esta última no quadro comparativo mais amplo da estrutura de classes como um todo e da respectiva composição.

Mais do que saber a percentagem de estudantes em trajectórias estacionárias ou ascendentes, por comparação com a condição de classe dos seus pais - aqui não podemos falar de trajectórias descendentes porque não há nenhum lugar de classe por referência ao qual a condição de estudante universitário represente despromoção social -, fica a saber-se, através do cálculo desses índices de recrutamento, as probabilidades diferenciais de se atingir a universidade a partir de cada um dos lugares de classe considerados.

Conhecendo o peso relativo dos contingentes de estudantes provenientes de cada categoria de classe e o peso relativo de cada uma dessas categorias na estrutura de classes global, podemos calcular uma medida agregada comparativa que nos diz quão mais fácil ou mais difícil é consegui-lo em cada classe de origem. ${ }^{7}$ Desde logo se vê que são os estudantes universitários provenientes do operariado aqueles que se encontram mais sub-representados. Se considerarmos igual a 1 o quociente entre a proporção de estudantes de famílias operárias e a proporção do operariado no conjunto da população nacional na faixa etária modal das famílias de origem, vemos que os quocientes homólogos para as restantes categorias de classe são sempre maiores ou mesmo muito maiores, à medida que se sobe na hierarquia dos lugares de classe.

\footnotetext{
${ }^{7}$ O índice de recrutamento de classe calcula-se dividindo, para cada categoria de origem de classe, o valor percentual dessa classe de origem na amostra dos estudantes pelo valor percentual da mesma categoria de classe na população nacional tomada como referência (população nacional na faixa etária modal das famílias de origem dos estudantes). Em seguida, para mais fácil interpretação, atribui-se o valor 1 à categoria com o resultado mais baixo, e recalcula-se o valor das outras categorias relativamente a essa base. O índice mostra, assim, a estrutura de oportunidades (probabilidades diferenciais) de acesso ao ensino superior (licenciatura) dos estudantes oriundos das diferentes classes sociais. Essas probabilidades diferenciais são expressas em valores inteiros multiplicativos daquele que corresponde à origem social com mais baixo nível de oportunidades verificado (Almeida, Costa e Machado, 1988; Machado, Ávila e Costa, 1995).
} 
Podemos, assim, dizer, por exemplo, que, em 2001, a probabilidade de os empresários, dirigentes e profissionais liberais ou os profissionais técnicos e de enquadramento, dos 45-54 anos, terem filhos na universidade é 7 ou 8 vezes maior do que a dos operários da mesma faixa etária, o que é uma medida expressiva da desigualdade de oportunidades entre as categorias em questão. Sem enviesamentos de natureza estritamente social, os estudantes de cada categoria de classe teriam o mesmo peso que essas categorias têm na estrutura de classes como um todo.

O estabelecimento de termos de comparação para a estrutura de classes global não pode deixar de ter em conta especificações metodológicas, seja a nível etário seja a nível temporal.

Com efeito, essa comparação não deve ser feita com a população em geral, mas apenas com aquela que está na mesma faixa etária em que se encontram os pais e mães dos estudantes no momento da observação. Este enquadramento geracional é indispensável, já que os perfis de classe tanto dos que estão acima como dos que estão abaixo desse escalão de idade - e consequentemente o perfil de classe do conjunto da população -, são a expressão de configurações da estrutura social que já não se reflectem, ou ainda não se reflectem, no perfil daqueles que pertencem a esse escalão. Tendo em conta a idade média dos estudantes no momento do inquérito e os calendários médios de fecundidade, podemos estimar que os seus pais se encontravam, com grande probabilidade, na faixa etária dos 25-34 anos, em 1981, data que corresponde aos primeiros anos de vida dos estudantes, e na faixa etária dos 45-54 anos, em 2001, correspondendo ao momento em que eles estão na universidade ou, tendo em conta que o inquérito é de 1999, acabaram de sair dela.

Quanto à opção por duas datas de referência para comparar a composição de classe das famílias de origem dos estudantes com a população portuguesa da mesma faixa etária, datas que se fez coincidir com momentos censitários de forma a dispor de dados equivalentes para a estrutura de classes global, ela justifica-se porque permite uma análise mais completa do que a que se obteria recorrendo a uma só data. $\mathrm{O}$ ano de 2001, sendo muito próximo do momento em que se observou o perfil de classe das famílias dos estudantes, ou melhor, os lugares de classe ocupados por essas famílias no momento em que os seus filhos estão na universidade, proporciona a comparação quase "em tempo real" desse perfil específico com o da população portuguesa da mesma faixa etária, permitindo aferir directamente distâncias e proximidades.

O ano de 1981, embora apenas de forma indirecta e hipotética, porque não se sabe que lugares de classe ocupavam os pais dos estudantes nessa data, fornece elementos comparativos complementares. Correspondendo 
à primeira infância dos inquiridos, e conhecendo-se, para essa data, a composição de classe da população portuguesa da faixa etária em que os pais desses estudantes estavam incluídos, pode avaliar-se retrospectivamente as possibilidades que os filhos de famílias das diferentes classes teriam de vir a tornar-se estudantes universitários, caso os lugares de classes dos grupos domésticos dos estudantes inquiridos fossem os mesmos que eram em 1999, o que só em parte será verdade.

Como se vê no Quadro 1, o índice de recrutamento de classe apresenta valores mais altos em 1981 e mais baixos em 2001, significando recrutamentos de classe mais fechados no primeiro caso e menos fechados no segundo. Por exemplo, em 2001, a probabilidade de um filho de empresários, dirigentes e profissionais liberais ser estudante universitário é "apenas" 7 vezes maior do que a de um filho de operários, enquanto em 1981, calculada na base hipotética já referida, de as famílias dos estudantes inquiridos ocuparem nessa data os mesmos lugares de classe que ocupavam no momento do inquérito, essa probabilidade é 35 vezes superior.

O que explica tão grande diferença de probabilidades é a recomposição muito considerável da estrutura de classes em Portugal entre as duas datas, que alterou substancialmente o perfil do segmento da população portuguesa que na primeira data tinha 25-34 anos e na segunda 45-54 anos, segmento que inclui os pais e mães dos estudantes inquiridos.

Presumindo que o segmento de população que tinha 25-34 anos, em 1981, e 45-54 anos, em 2001, é composto no essencial pelas mesmas pessoas, ou seja, abstraindo aqui o efeito das migrações, pode depreender-se, embora só a pesquisa directa sobre os trajectos das famílias dos estudantes o pudesse comprovar com segurança, que essas famílias acompanharam de forma modal a recomposição classista da geração de que fazem parte, o que significará que o percurso escolar que levou os seus filhos à universidade foi a par, em muitos casos, de trajectos familiares de mobilidade social ascendente, pura ou decorrente da mobilidade estrutural.

Seja como for, mesmo com os índices de recrutamento menos assimétricos, a leitura que pode fazer-se do Quadro 1 mostra que as probabilidades de aceder à condição de estudante universitário são bastante desiguais conforme as categorias de classe de origem, formando-se um contínuo que tem o extremo menos favorável nas famílias operárias e o mais favorável nas famílias de empresários, dirigentes e profissionais liberais e nas de profissionais técnicos e de enquadramento.

Se a dimensão da amostra o permitisse, seria interessante observar, a este propósito, como se dá a distribuição das origens sociais dos estudantes pelas três fracções da classe de topo, os empresários, os dirigentes e os profissionais liberais, sabendo-se que estes últimos se aproximam dos profissio- 
nais técnicos e de enquadramento pelo lado dos capitais escolares e culturais, e conhecendo-se a influência que a "herança" desse tipo particular de recursos tem na produção de carreiras escolares mais longas.

A análise das origens de classe dos estudantes universitários de acordo com o sexo, por seu lado, revela resultados que podem ser directamente relacionados com o que a sociologia da educação tem mostrado ser, no plano tanto internacional e como nacional, o melhor desempenho escolar feminino, nos vários níveis de ensino (Baudelot e Establet, 1992; Grácio, 1997; Durut-Bellat, Kiefer e Marry, 2001). De facto, embora por diferenças pequenas, mas sempre para o mesmo lado, as estudantes de famílias de menores recursos (AEpl, O, EE, TIpl e TI) que conseguem atingir o ensino universitário são em geral mais do que os seus pares masculinos.

Mesmo quando se consideram os seus pais e mães separadamente, e se perde portanto a lógica da agregação dos grupos domésticos, esse efeito relativo à diferença sexual é visível. De que forma é que ele está ligado aos desempenhos escolares diferenciais de rapazes e raparigas? O que parece passar-se é que, devido ao melhor desempenho feminino na escola, o recrutamento de raparigas para a universidade se torna um pouco menos dependente da origem de classe do que o dos rapazes, possibilitando mais acessos a partir de posições mais distantes do mundo da universidade. Por isso mesmo, os índices de recrutamento de classe masculinos são sistematicamente mais selectivos do que os femininos.

\section{Efeitos do capital escolar}

Sem perder de vista o carácter multidimensional das desigualdades de classe, e as combinações múltiplas e complexas entre as várias dimensões relevantes, deve notar-se que as desigualdades de qualificações escolares, e de competências em geral, são hoje particularmente decisivas no jogo das oportunidades e obstáculos sociais.

Por isso mesmo, é pertinente analisar agora as origens socio-educacionais dos estudantes universitários e a respectiva comparação com o perfil escolar da população portuguesa (Quadro 2). Se, para analisar os elementos empíricos anteriores, nos colocámos ao nível dos "lugares de classe" ocupados pelos seus grupos domésticos de origem social, a observação dos capitais escolares das famílias desses estudantes coloca-nos a num outro nível de análise, que é o da formação de "classes de agentes", portadores de determinados recursos individuais e familiares, neste caso recursos de natureza escolar. ${ }^{8}$

\footnotetext{
${ }^{8}$ A respeito da pertinência da distinção destes dois objectos de análise, diferentes mas complementares, ver Costa et al., 2000).
} 
Como se apresentam, então, as escolaridades de origem dos estudantes? Um pouco mais de um terço deles provém de grupos domésticos com ensino superior. Se lhes juntarmos aqueles cujas famílias têm o ensino secundário, atingimos mais de metade da amostra, o que nos permite dizer, numa primeira comparação genérica com a população portuguesa, fracamente escolarizada, como é sabido, que esses estudantes são oriundos de meios sociais com capitais escolares muito acima da média nacional. Em contraponto a esse tipo de origem socio-educacional, temos também, no entanto, uma percentagem considerável de estudantes cujas famílias não têm mais do que o $1 .^{\circ}$ ciclo do ensino básico. Se somarmos as três componentes do que é hoje o ensino obrigatório, encontramos a outra metade da distribuição.

Ou seja, reaparece aqui, ainda com mais nitidez, algo de que já se tinha dado conta na análise das origens de classe: na categoria dos estudantes universitários há um duplo padrão de recrutamento social, ainda que assimétrico. Os meios sociais dotados de mais recursos, neste caso recursos escolares, estão mais representados do que os meios deles mais desmunidos, mas a presença destes está longe de ser residual.

Antes de compararmos de maneira mais rigorosa a escolaridade das famílias dos inquiridos com a da população portuguesa, importa ter em conta o tipo de distribuição de capital escolar de origem que se obtém quando se toma como unidade de análise não o grupo doméstico, mas os indivíduos isoladamente considerados, isto é, o somatório total de pais e mães independentemente dos respectivos vínculos conjugais. Nesta leitura individual, a distribuição sofre alterações consideráveis. Os mais frequentes passam a ser os indivíduos com o 1 . $^{\circ}$ ciclo do ensino básico, ficando os titulares de ensino superior em segundo lugar.

Há, portanto, um efeito de "inflação" dos capitais escolares das famílias quando se usa a unidade de análise grupo doméstico, que é resultado do facto de também aqui se ter aplicado o critério da dominância utilizado no cálculo das localizações de classe familiares. Tomou-se como nível de escolaridade da unidade familiar o do elemento mais escolarizado do núcleo conjugal. Se é verdade que, perante esta opção, pode objectar-se que os grupos domésticos não têm escolaridade, mas que são os indivíduos que os compõem que a têm, importa ter em conta que, no contexto de socialização familiar, esses capitais culturais mais elevados tenderão a constituir os recursos disponíveis de referência prática.

Para comparar as qualificações académicas das famílias de origem dos estudantes com as da população portuguesa, procedeu-se segundo uma metodologia similar à utilizada aquando da análise das origens de classe. Construíram-se, desta vez, índices de recrutamento escolar, que, sob as es- 
pecificações etárias e temporais também antes estabelecidas, permitem avaliar distâncias e proximidades entre as competências escolares dos pais dos estudantes e as dos portugueses em geral. Fica, assim, a saber-se quais as probabilidades de se atingir a universidade partindo de famílias com montantes desiguais de capital escolar.

Temos, então, que, igualando à unidade a probabilidade de um filho de analfabetos atingir a universidade, probabilidade essa muito pequena, dado que, sendo os analfabetos ainda 10\% dos portugueses de $45-54$ anos, em 2001, apenas $2 \%$ dos estudantes tinham pais e/ou mães nessa situação, o acesso à universidade vai-se tornando cada vez mais provável à medida que se sobe na hierarquia do capital escolar. O caso de máxima desigualdade de oportunidades é o que, com base nos dados da população portuguesa para 1981, opõe filhos de famílias com ensino superior e filhos de famílias de iletrados, os primeiros com 55 vezes mais hipóteses de chegar à universidade do que os segundos.

Pelas razões já adiantadas, que têm a ver com a aplicação do princípio da dominância na determinação da composição escolar das famílias de origem, os índices de recrutamento escolar são mais desequilibrados quando se toma como unidade de análise o grupo doméstico do que quando se opta pela unidade de análise individual. Por outro lado, eles também são mais desproporcionados quando se considera como data de referência o ano de 1981 em vez do ano de 2001.

Neste particular, a diferença é resultado do próprio trajecto escolar global da população portuguesa entre as duas datas no que toca às qualificações escolares. Não só os portugueses como um todo aumentaram os seus níveis de escolaridade, mas, mais importante do que isso e mais directamente relevante para a nossa comparação, a geração a que pertencem os pais dos estudantes inquiridos, aquela que em 1981 tinha 25-34 anos e, em 2001, 45-54 anos, também os aumentou.

Considerando-se, como já atrás se fez, que os efeitos das migrações externas, no período em análise e dentro do intervalo de idades em causa, são residuais, podemos dizer que estamos, no essencial, perante o mesmo conjunto de pessoas em duas datas e em dois escalões etários diferentes. Comparando as duas distribuições, vê-se que os detentores de ensino superior aumentam quase três pontos percentuais, o que representa um crescimento muito substantivo, o mesmo acontecendo com os que têm ensino secundário. Ou seja, nesta geração, muitos adultos, incluindo certamente pais e mães dos estudantes inquiridos, estiveram posteriormente no sistema de ensino, eventualmente após terem interrompido as suas trajectórias escolares em algum momento quando eram mais novos. 
O pano de fundo social em questão não é, portanto, apenas, o de jovens que fazem o seu percurso académico até à universidade tendo pais e mães geralmente muito menos escolarizados do que eles e que estudaram só quando eram crianças ou, quando muito, até à juventude, mas também o de famílias em que pais e/ou mães e filhos estão todos, numa certa fase, no sistema de ensino, por vezes no mesmo segmento desse sistema, o que não deixará, certamente, de gerar efeitos de interacção positiva, se é que essa concomitância não é já ela própria um efeito de exemplo intrafamiliar.

Tal como no plano das origens de classe, também no que às origens socio-educacionais diz respeito a importância da variável sexo é notória. Seja a unidade de análise o grupo doméstico ou o indivíduo, há sempre percentagens um pouco maiores de raparigas com pais pouco escolarizados.

Os efeitos dessa variável vão no mesmo sentido dos observados anteriormente. Se, no que toca às origens de classe, vimos que as estudantes são comparativamente mais recrutadas em níveis mais desfavorecidos da estrutura de classes, o que atribuímos ao facto de o melhor desempenho médio feminino na escola compensar, em alguma medida, essa desvantagem comparativa, agora, que está justamente envolvido o capital cultural transmitido pelas famílias, aquele que muito directamente influencia a aquisição do capital escolar no sistema de ensino, essa diferença torna-se ainda mais evidente. As raparigas revelam-se um pouco mais capazes de superar a falta desse capital do que os rapazes.

\section{Origens de classe, sexo e áreas científicas}

O ensino universitário é, hoje em dia, um campo internamente muito diferenciado, desde logo em função da oferta pública ou privada, mas também quanto à distribuição regional das universidades, sua dimensão, antiguidade ou número de vagas por curso. Mas um dos principais eixos de diferenciação interna do sistema universitário é, sem dúvida, o que tem a ver com a sua repartição em grandes áreas de conhecimento, cada uma das quais, por sua vez, é também diversa no seu interior. Seja no valor de mercado dos títulos académicos, seja no plano do prestígio ou capital simbólico que lhes está associado, essa diferenciação converte-se numa verdadeira variável de estratificação interna do campo universitário.

Dada essa estratificação interna das áreas de conhecimento, como é que as origens de classe dos estudantes universitários se articulam com ela? Dito de outra forma, que combinações se geram entre estratificação externa dos estudantes e estratificação interna do sistema universitário? E, no que respeita à variável sexo, que distribuições podem observar-se? Finalmente, que tipo de relações existem entre classes de origem e sexo, por um lado, e tipo de ensino, púbico ou privado, por outro? 
Relativamente a este último ponto, verifica-se uma diferença importante na distribuição comparativa dos estudantes provenientes de grupos domésticos pertencentes às duas categorias de classe privilegiadas, os empresários, dirigentes e profissionais liberais, por um lado, e os profissionais técnicos e de enquadramento, por outro. Os primeiros encontram-se mais no ensino privado e os segundos no ensino público.

As razões desta distribuição particular prender-se-ão, provavelmente, com a posse diferencial de capitais culturais e escolares por parte de cada uma dessas categorias de classe. Poderá dizer-se que, para além da selecção social primária, que faz com que os alunos das classes populares cheguem pouco à universidade, se processa uma selecção social secundária, dentro das classes dominantes e das classes médias, agora de acordo com o volume de capital cultural.

Num primeiro olhar, poderia associar-se a maior presença de filhos de empresários, dirigentes e profissionais liberais no ensino privado ao respectivo capital económico. Mas pode ser uma interpretação enganadora. Os custos envolvidos na frequência de uma universidade privada não constituem obstáculo decisivo para as famílias de profissionais técnicos e de enquadramento, também bem dotadas de capital económico. A explicação estará, portanto, não tanto no capital que os filhos de EDL têm em maior quantidade, o económico, mas sobretudo naquele em que são comparativamente deficitários, o cultural. E vale a pena ter em conta que, em Portugal, as universidades privadas não serão globalmente procuradas em função de um eventual prestígio superior às públicas.

Percorramos agora aos dados centrais do Quadro 3, relativos à distribuição dos estudantes por áreas de conhecimento segundo a sua origem de classe. A hierarquia de prestígio socialmente atribuído às áreas de estudo universitário e aos mundos profissionais a que elas dão acesso - hierarquia que, grosso modo, tem o topo nas ciências médicas e a base nas letras e nas ciências sociais, o que não tem só a ver com o valor de mercado dos respectivos títulos académicos, mas também com a dimensão da oferta de vagas e outros factores -, é redobrada pela hierarquia das procuras sociais dessas áreas a partir das diferentes classes. Os estudantes provenientes de classes de maiores recursos distribuem-se de forma totalmente homóloga a essa distribuição de capital simbólico, contribuindo, dessa forma, para a reproduzir.

Se tomarmos em conjunto os estudantes de famílias de EDL com os de famílias de PTE, verificamos que os valores obtidos variam entre uma presença relativa máxima na área das ciências médicas e mínima nas letras e artes. As engenharias e o direito aparecem a seguir às ciências médicas, mas já a considerável distância, vindo depois a economia e gestão, as ciências naturais, a matemática e as ciências sociais. 


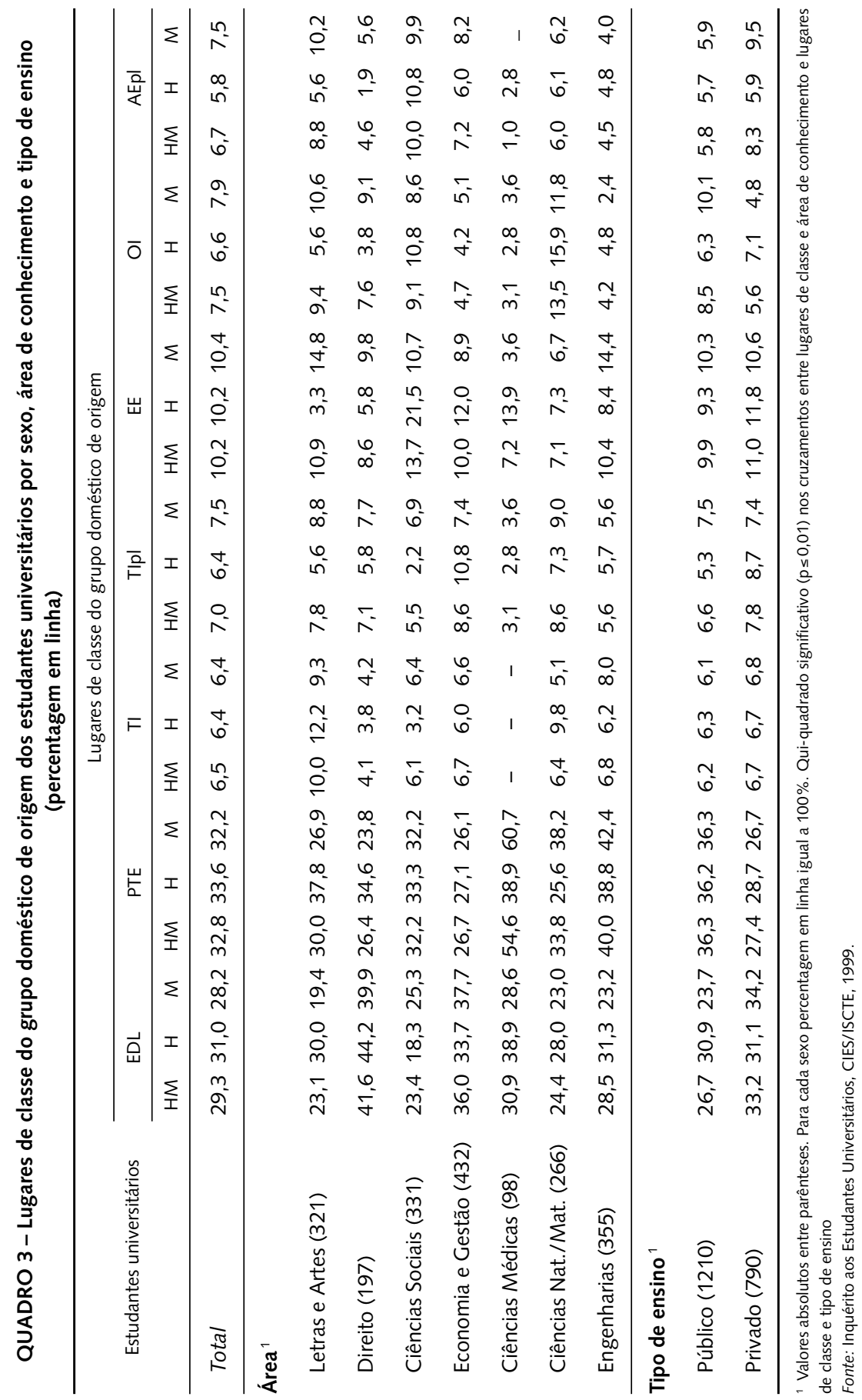


Em contrapartida, as áreas de estudo habitualmente menos cotadas nessa escala de prestígio são aquelas em que os estudantes de sectores sociais mais desfavorecidos estão presentes em valores acima da média: os filhos de empregados executantes, especialmente os de sexo masculino, nas ciências sociais; os filhos de operários, nas ciências naturais e matemática; os filhos de assalariados executantes pluriactivos, também nas ciências sociais.

Entre os dois sectores de classe liderantes há, contudo, variações importantes. Assim, enquanto os filhos de EDL relegam as ciências sociais para as últimas escolhas, juntamente com as ciências naturais e a matemática, os filhos de PTE, apesar de serem os que mais conseguem entrar nos cursos mais exclusivos, como as ciências médicas e as engenharias, demonstram, ao mesmo tempo, um nível razoável de procura das ciências sociais, deixando antes para o fim da lista a economia e gestão e o direito, justamente aquelas que os filhos de EDL mais procuram.

Essas duas categorias de classe, EDL e PTE, têm, na sociedade portuguesa, o que, em trabalhos anteriores, se designou por protagonismos sociais contrastantes (Almeida, Costa e Machado, 1994; Machado e Costa, 1998). O primeiro desses sectores é mais velho, menos escolarizado e mais masculino; o segundo é mais feminino, mais jovem e mais escolarizado. Um e outro têm crescido nas últimas décadas em Portugal, mas por vias largamente dissociadas, respectivamente, as actividades empresariais, de escala pequena ou média, e os estudos universitários. A distribuição dos estudantes oriundos de cada um desses sectores por áreas científicas pode ser lida à luz desses protagonismos sociais contrastantes e de estratégias de reconversão e reprodução a eles associadas.

Veja-se que, num plano inferior da estrutura de classes, também os oriundos de famílias ligadas ao trabalho por conta própria se orientam um pouco mais para a economia e a gestão do que para outras áreas, em homologia com os filhos de empresários, dirigentes e profissionais liberais, homologia que, como Bourdieu (1979) mostrou, é mais ampla, estendendo-se a outros domínios das representações e práticas sociais.

Outro aspecto que vale a pena destacar, no tocante às categorias de classe minoritariamente representadas, é o relativo aos estudantes oriundos de famílias de empregados executantes. Entre todas as categorias subalternas, são eles os que, apesar de tudo, mais chegam aos cursos socialmente mais selectivos, concretamente ciências médicas e engenharias, o que tem a ver, com toda a probabilidade, com a sua vantagem relativa quanto ao capital escolar de origem. Uma vez mais, como se vê, e como já atrás se mencionou, justifica-se plenamente a autonomização desse sector de classe relativamente ao conjunto mais vasto em que autores como Wright (1997) o diluem. 
Apesar de a variável sexo não ter sido critério de amostragem, a distribuição global de homens e mulheres por áreas científicas na amostra assemelha-se, nos contornos gerais, àquela que é conhecida para o universo dos estudantes universitários. As estudantes são maioritárias em termos gerais e, no que toca à distribuição por áreas de estudo, só as engenharias fogem claramente à regra da maioria feminina.

Mas de que forma é que a composição sexual se combina, neste plano, com as origens de classe? Vimos anteriormente que a origem de classe das estudantes tem um perfil um pouco diferente, para baixo, do dos seus pares masculinos e, também, que elas provêm de famílias com capitais escolares um pouco menos elevados. A interpretação avançada para esse facto foi no sentido de que, sendo o desempenho escolar médio das raparigas superior ao dos rapazes, o seu acesso à universidade é um pouco menos dependente da origem de classe e socio-educacional do que o dos rapazes, sendo elas, portanto, mais do que eles, recrutadas em sectores sociais menos providos de recursos. Será que também aqui se verifica esse efeito? Tendo em conta a estratificação interna das áreas de conhecimento, será que as estudantes vindas dos segmentos mais desfavorecidos conseguem, mais do que os rapazes, atingir as áreas mais inacessíveis?

Observando os resultados apresentados no Quadro 3, verifica-se que só em parte isso é verdade. Nas três áreas que ocupam o topo da estratificação, não só pelo valor de mercado e pelo capital simbólico que lhes estão associados, mas também por serem aquelas em que, por isso mesmo, os filhos de EDL e PTE estão em maior número, ou seja, ciências médicas, engenharias e direito, há distribuições de sinal contrário.

Nas engenharias e no direito, verifica-se, com efeito, que as estudantes oriundas do conjunto das categorias de classe com menos recursos são mais do que os estudantes, que vêm em maior proporção do conjunto formado pelas famílias de EDL e PTE. A diferença no caso do direito é particularmente expressiva.

Já para as ciências médicas, que tem sido a mais selectiva de todas as áreas de formação, a distribuição é contrária à tendência geral. Aí, as raparigas dos sectores mais desfavorecidos são apenas $11 \%$, contra $22 \%$ dos rapazes. Ou, dito ao contrário, $89 \%$ das estudantes de ciências médicas provêm de famílias de EDL e PTE, contra 78\% dos estudantes.

Uma última nota, só para mencionar a distribuição dos estudantes dos dois sexos pelo ensino público e privado, em função das origens de classe. No ensino público, socialmente mais selectivo, em geral, devido às notas de acesso, as estudantes dos sectores de classe com menos recursos são proporcionalmente mais do que os rapazes, enquanto no ensino privado os valores homólogos são praticamente iguais. 


\section{Orientação de vida}

Em consonância com o modelo de análise apresentado no início do artigo, que aponta para o estudo de determinados atributos sociais e culturais dos estudantes universitários e para as relações que entre esses atributos se estabelecem, o último conjunto de resultados empíricos aqui analisados é referente às orientações de vida desses estudantes, a partir do indicador patente na Figura 4, e das relações entre essas orientações e o lugar de classe dos grupos domésticos de origem, escolaridade de origem, sexo e área científica de estudo (Quadro 4).

FIGURA 4 - Indicador de modelos de orientação de vida dos estudantes universitários

QUOTIDIANO

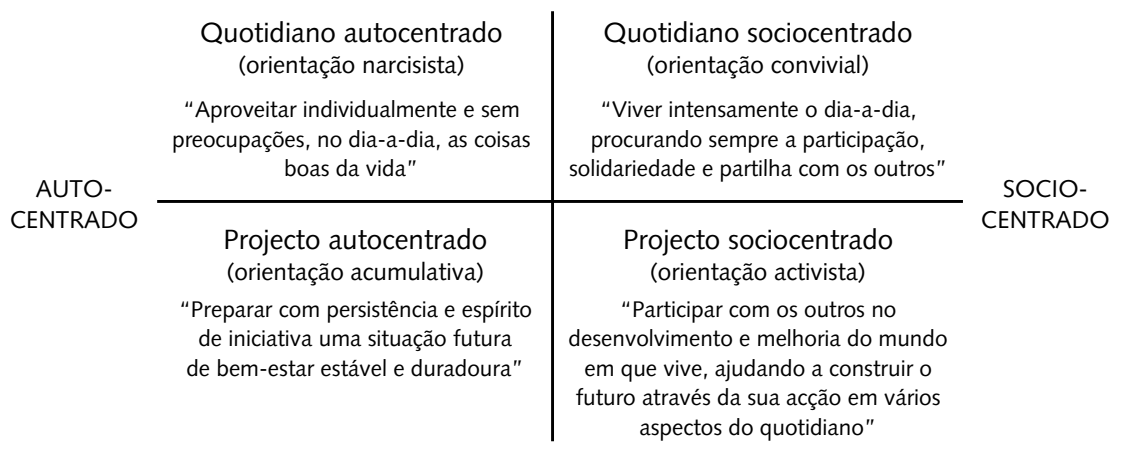

PROJECTO

O indicador das orientações de vida, elaborado em meados dos anos 80, no início do já mencionado programa de investigação sobre estudantes universitários em Portugal, tem sido usado em diversos momentos deste programa (Costa, Machado e Almeida, 1990), bem como noutras pesquisas empíricas em Portugal (Estanque e Nunes, 2002). É um indicador integrado, que procura captar grandes linhas de força estruturadoras dos quadros simbólico-ideológicos dos agentes sociais, a partir do cruzamento de dois eixos importantes - o eixo quotidiano-projecto e o eixo autocentramento-sociocentramento -, gerando quatro tipos de orientações: quotidiano autocentrado, ou orientação narcisista; projecto autocentrado, ou orientação acumulativa; quotidiano sociocentrado, ou orientação convivial; projecto sociocentrado ou orientação activista.

O conceito de orientações de vida, que este indicador procura operacionalizar, tem duas componentes: uma mais puramente disposicional, no sentido do conceito de habitus de Pierre Bourdieu, com o seu carácter 


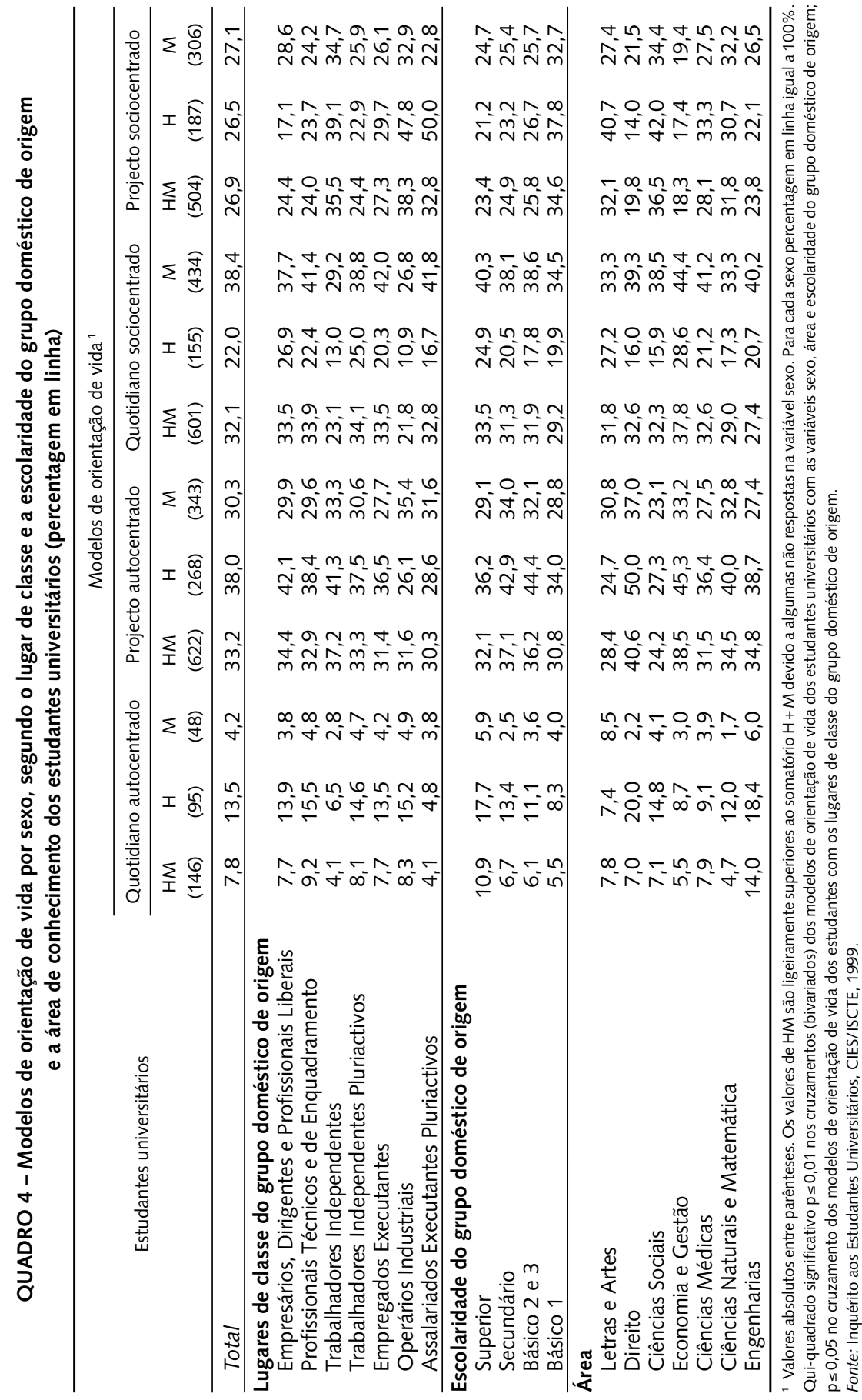


inconsciente e "automático", reflectindo condições de existência e trajectórias de classe, e outra mais reflexiva, de orientação racional da acção, sensível tanto aos enquadramentos estruturais como às configurações culturais observáveis nas sociedades contemporâneas e respectivas flutuações e mudanças. Pela sua natureza multidimensional e sintética, o indicador das orientações de vida pode ser tomado para as configurações simbólico-culturais do mesmo modo que se tomam os indicadores socioprofissionais para as estruturas de classes.

Como se vê no Quadro 4, todas as modalidades do indicador têm expressão quantitativa entre os estudantes universitários, embora uma delas se situe num patamar bastante abaixo das restantes. À diferenciação de origens sociais, soma-se, portanto, uma diferenciação simbólico-cultural, que só em parte, como veremos, depende dessa diversidade de meios de origem.

Dos quatro modelos de orientação de vida, sobressaem, praticamente a par um do outro, o "projecto autocentrado" ou orientação acumulativa $(33 \%)$ e o "quotidiano sociocentrado" ou orientação convivial (32\%), o que, dado o forte contraste entre eles, desde logo revela profunda heterogeneidade nos quadros simbólico-culturais dos estudantes; o "projecto sociocentrado" ou orientação activista regista um valor também importante, mas num patamar quantitativo abaixo do anterior; o "quotidiano autocentrado" ou orientação narcisista tem expressão muito mais fraca, mas não propriamente residual.

A variação das orientações de vida em função do lugar de classe do grupo doméstico de origem não é muito forte. Os estudantes de famílias de EDL e de PTE estão sensivelmente dentro do padrão geral, embora os primeiros apareçam um pouco mais inclinados para a orientação acumulativa e os segundos para a orientação convivial. Os filhos de trabalhadores independentes surgem também ligeiramente acima da média na primeira daquelas orientações e bastante abaixo da média na segunda, a benefício de uma opção comparativamente mais frequente pela orientação activista.

Onde uma marca de "cultura de classe" parece evidenciar-se é no caso dos estudantes oriundos do operariado, claramente acima da média na orientação activista, sendo que, paralelamente, estão perto dos valores médios da orientação acumulativa. Entre todos, são eles os que menos se identificam com a orientação convivial, aspecto em que se aproximam dos filhos de trabalhadores independentes.

Se as correlações com o indicador classista são relativamente ténues, com o indicador de capital escolar das famílias de origem já são um pouco mais sólidas. Os estudantes de famílias com o nível mínimo de escolaridade, o antigo ensino primário, afastam-se visivelmente do padrão médio, ao colo- 
carem em primeiro lugar, e com valores mais elevados do que todos os restantes inquiridos, o projecto sociocentrado. Em parte, esta correlação recobre a que acabámos de verificar entre esta mesma orientação de vida e a origem operária.

No patamar de escolaridades acima deste, o tipo de orientação prevalecente é outro. Os descendentes de famílias com o $2 .^{\circ}$ e o $3 .^{\circ}$ ciclo de ensino básico e com o ensino secundário privilegiam o projecto autocentrado mais do que qualquer outro modelo. No que se refere aos estudantes cujas famílias se situam no patamar do ensino superior, as orientações convivial e acumulativa reúnem grande parte das preferências, tal como acontece em termos médios.

A diferença de modelos de orientação de vida em função do sexo, por sua vez, é notória, podendo mesmo falar-se de quadros simbólico-culturais contrastantes. A orientação mais escolhida pelos estudantes de sexo masculino é a acumulativa, ao passo que as estudantes elegem a orientação convivial. Esta última opção é particularmente diferenciadora, já que, no caso dos rapazes, ela só aparece como terceira escolha, a grande distância percentual. Embora minoritária, também a orientação narcisista, claramente mais masculina (e aí nitidamente crescente com o nível de ensino), marca muito fortemente a diferença entre sexos, só havendo acordo no que toca à orientação activista, mencionada por proporções quase iguais de rapazes e raparigas.

A combinação do sexo com a origem de classe mostra aspectos adicionais interessantes. A orientação convivial é especialmente escolhida pelas alunas provenientes de famílias de PTE e EE, a orientação acumulativa é mais notória entre os estudantes de famílias de EDL e TI, ao passo que no caso dos de origem operária há um padrão de contraste entre sexos: eles têm uma orientação marcadamente activista; elas, sem deixarem de dar importância a essa orientação, destacam-se pela orientação acumulativa.

Entre todas as variáveis em análise, aquela que regista correlações mais fortes com as orientações de vida é, contudo, a relativa à área de conhecimento, que, para além de ser uma linha importante de estratificação social, aparece, também, como um revelador e um factor de diferenciação ou mesmo de contraste entre modelos simbólico-culturais.

Se os estudantes de ciências médicas manifestam preferências muito semelhantes ao padrão médio, já os de direito, economia e gestão, por um lado, e os de ciências sociais e letras e artes, por outro, encontram-se em posições muito distantes do espaço ideológico captado pelo indicador das orientações de vida. Assim, enquanto os primeiros se colocam bem acima da média na orientação acumulativa, remetendo para plano muito secundário 
a orientação activista; os segundos, mais ainda os de ciências sociais do que os de letras e artes, fazem exactamente o contrário, colocando a orientação activista em primeiro lugar, bem distante da acumulativa.

Parece estarmos aqui perante o que poderíamos designar por "ideologias de curso" que contribuirão fortemente para modelar os quadros de valores dos estudantes, sendo certo que a própria escolha de um determinado curso em vez de outro já pode ser entendida como sinal prévio de afinidades culturais. Deve, notar-se, finalmente, e esse é outro ponto interessante, que essas ideologias de curso não envolvem de forma igual os estudantes dos dois sexos. Quer a orientação acumulativa dos estudantes de direito e economia e gestão, quer a orientação activista dos que estudam ciências sociais e letras e artes são bastante mais masculinas do que femininas.

\section{Notas conclusivas}

No actual debate público sobre políticas educativas e no novo senso comum mediático, tem vindo a ser insistentemente proposta a ideia de que, na sociedade portuguesa contemporânea, o ensino universitário teria crescido de forma excessiva e, em consequência, haveria licenciados a mais.

O crescimento é um facto. Desde 1974, o número de estudantes no ensino superior praticamente decuplicou, passando da ordem dos 46 mil, em 1970 para a dos 391 milhares, em 2001. ${ }^{9}$ Mas que seja um crescimento excessivo, já é muito discutível. Em que consistiria o "excesso"?

O crescimento, em si mesmo, revela apenas o extraordinário atraso, no contexto europeu, de que, à entrada do último quartel do século XX e do ciclo democrático iniciado com o 25 de Abril, a sociedade portuguesa partia, quanto às qualificações da sua população. $O$ ensino universitário restringia-se então a uma faixa extremamente minoritária da população, constituindo o diploma garantia inquestionada de um status social de elite. Excessivo, pois, era o atraso educativo anterior.

E actualmente? Vista pelo lado das comparações internacionais - base operativa mínima para analisar a questão, com algum fundamento empírico, no âmbito dos processos de desenvolvimento de uma sociedade da informação e do conhecimento crescentemente globalizada - a situação é tudo menos de excesso de qualificações. Com efeito, apesar do crescimento do número de estudantes, não chegam aos $12 \%$ os que, na população do país com idades entre 25 e 64 anos (a mais centralmente activa), possuem um diploma do ensino superior (INE, Censos 2001). Em comparação, a média

\footnotetext{
${ }^{9}$ Fonte: Estatísticas da Educação e Recenseamentos Gerais da População, INE.
} 
da União Europeia (UE15), na mesma data, é de 22\%. Países considerados com nível de desenvolvimento mais próximo do português apresentam valores de 18\% (Grécia), 21\% (Irlanda) ou 24\% (Espanha). ${ }^{10}$ Isto para já não falar de casos como o da Finlândia (32\%), Reino Unido (29\%), Bélgica $(28 \%)$ ou Dinamarca $(27 \%)$.

Nas gerações mais novas, a situação melhora, como seria de esperar, mas não muito, o que contraria a imagem publicamente mais difundida. $\mathrm{Na}$ faixa etária dos 25 aos 34 anos, a percentagem de diplomados pelo ensino superior não chega aos 17\% (INE, Censos 2001). Estabelecendo as mesmas comparações com os países de nível de desenvolvimento mais próximo, encontram-se os valores de 23\% (Grécia), 31\% (Irlanda) e 37\% (Espanha): a distância cresce. A média da UE15 é de $27 \%$. Portugal continua, nos mais jovens, com 10 pontos percentuais menos.

É evidente a situação fragilizada do país perante a crescente importância dos saberes e competências de nível elevado nos processos de inovação tecnológica, competitividade económica, afirmação cultural, cidadania política e bem-estar social.

Como é possível verificar-se, ainda assim, desemprego de licenciados? A resposta, em termos gerais, assenta numa combinação de dois factores: por um lado, num tecido económico com um nível e um ritmo de qualificação ainda mais fracos do que os da população; por outro lado, numa concepção, ainda socialmente prevalecente, do diploma universitário mais como um suposto garante de um status de elite minoritária do que como um instrumento, hoje em dia relativamente corrente e cada vez mais necessário, para um leque diversificado de padrões de vida pessoal, profissional, cultural e cívica.

É neste quadro que se inserem os resultados de investigação sociológica atrás apresentados. Verificou-se como o alargamento do ensino superior correspondeu ao efectivo estabelecimento de um duplo padrão de recrutamento social dos estudantes universitários, com um importante segmento de reprodução no topo, mas também com um significativo segmento de mobilidade social ascendente. Determinou-se um padrão de probabilidades diferenciais de acesso ao ensino universitário, consoante a classe social e a escolaridade das famílias de origem, estimando essas probabilidades através da construção de índices de recrutamento. Evidenciou-se o modo como, nas trajectórias de escolarização universitária, os efeitos da variável sexo se articulam actualmente, na sociedade portuguesa, com os de classe social.

${ }^{10}$ Estes dados internacionais e os seguintes são do Eurostat, 2002. 
Além disso, relacionou-se este conjunto de desigualdades de classe e de sexo com alguns parâmetros fortes de estratificação interna do campo universitário, em termos de áreas de estudos e subsistemas público/privado. $\mathrm{E}$ analisou-se um conjunto de modelos de orientação de vida adoptados pelos estudantes inquiridos, assim como as respectivas conexões com composições sociais (origem de classe e sexo) e configurações culturais (dos cursos).

Mas importa ainda sublinhar que, num plano subjacente a estas análises substantivas, se encontra a elaboração de uma perspectiva teórica e de um conjunto de procedimentos operatórios para a análise das relações de classe nas sociedades contemporâneas. Não se confinando a cada caso específico, as respectivas potencialidades analíticas aferem-se e aperfeiçoam-se porém, precisamente, pela aplicação a objectos de estudo como o que aqui nos ocupou.

\section{Referências Bibliográficas}

Almeida, Ana Nunes de (1993), A Fábrica e a Família: Famílias operárias no Barreiro. Barreiro: Câmara Municipal do Barreiro.

Almeida, João Ferreira de (1986), Classes sociais nos campos: Camponeses parciais numa região do Noroeste. Oeiras: Celta.

Almeida, João Ferreira de; Costa, António Firmino da; Machado, Fernando Luís (1988), "Famílias, estudantes e universidade: painéis de observação sociográfica", Sociologia, Problemas e Práticas, 4, 11-44.

Almeida, João Ferreira de et al. (no prelo), Diversidade na Universidade: Um inquérito aos estudantes de licenciatura. Oeiras: Celta.

Almeida, João Ferreira de; Costa, António Firmino da; Machado, Fernando Luís (1994), "Recomposição social e novos protagonismos", in António Reis (org.), Portugal: 20 anos de Democracia. Lisboa: Círculo de Leitores, 307-330.

Almeida, João Ferreira de et al. (1996), Jovens de hoje e de aqui: Resultados do inquérito à juventude de Loures. Loures: Câmara Municipal de Loures.

Alves, Natália (2001), Trajectórias académicas e de inserção profissional dos licenciados, 1994-1998. Lisboa: Universidade de Lisboa/Gabinete de Apoio ao Estudante.

Balsa, Casimiro Marques et al. (2001), Perfil dos estudantes do Ensino Superior: Desigualdades e diferenciação. Lisboa: Edições Colibri.

Baudelot, Christian; Establet, Roger (1992), Allez les filles!. Paris: Maspéro.

Bernstein, Basil (1975), Langage et classe sociale: Codes socio-linguistiques et contrôle social. Paris: Les Éditions de Minuit.

Boudon, Raymond (1973), L'inégalité des chances: La mobilité sociale dans les sociétés industrielles. Paris: Armand Colin. 
Bourdieu, Pierre (1979), La distintion: Critique sociale du jugement. Paris: Les Éditions de Minuit.

Bourdieu, Pierre; Passeron, Jean-Claude (1964), Les héritiers: Les étudiants et la culture. Paris: Les Éditions de Minuit.

Bourdieu, Pierre; Passeron, Jean-Claude (1970), La réproduction: Éléments pour une théorie du système d'enseignement. Paris: Les Éditions de Minuit.

Cabral, Manuel Villaverde et al. (1998), Jovens portugueses de boje. Oeiras: Celta.

Casanova, José Luís (1993), Estudantes universitários: Composição social, representações e valores. Lisboa: Instituto de Ciências Sociais da Universidade de Lisboa e Instituto da Juventude.

Coleman, James S. et al. (1966), Equality of Educational Opportunity. Washington: Government Printing Office.

Costa, António Firmino da (1998), "Classificações sociais”, Leituras, 2, 65-75.

Costa, António Firmino da (1999), Sociedade de bairro: Dinâmicas sociais da identidade cultural. Oeiras: Celta.

Costa, António Firmino da; Machado, Fernando Luís; Almeida, João Ferreira de (1990), "Estudantes e amigos: trajectórias de classe e redes de sociabilidade", Análise Social, XXV(105-106), 193221.

Costa, António Firmino da et al. (2000), "Classes sociais na Europa”, Sociologia, Problemas e Práticas, 34, 9-46.

Crompton, Rosemary (2003), “Class and Gender beyond the 'Cultural Turn'”, Sociologia, Problemas e Práticas, 42, 9-24.

Cruz, Manuel Braga da et al. (1995a), O desenvolvimento do Ensino Superior em Portugal: A PGA e os estudantes ingressados no Ensino Superior. Lisboa: Instituto de Ciências Sociais da Universidade de Lisboa e Ministério da Educação/DEPGEF.

Cruz, Manuel Braga da et al. (1995b), O desenvolvimento do Ensino Superior em Portugal: Situação e problemas de acesso. Lisboa: Instituto de Ciências Sociais da Universidade de Lisboa e Ministério da Educação/DEPGEF.

Derouet, Jean-Louis (2002), “A sociologia das desigualdades em educação posta à prova pela segunda explosão escolar: deslocamento dos questionamentos e reinício da crítica”, Revista Brasileira de Educação, 21, 5-16.

Desrosières, Alain; Thévenot, Laurent (1988), Les catégories socioprofessionnelles. Paris: La Découverte.

Durut-Bellat, Marie (2002), Les inégalités sociales à l'école: Genèse et mythes. Paris: PUF.

Duru-Bellat, Marie; Kieffer, Annick ; Marry, Catherine (2001), "La dynamique des scolarités des filles: le double handicap questionné”, Revue Française de Sociologie, 42(2), 251-280.

Eder, Klaus (1993), The New Politics of Class: Social Movements and Cultural Dynamics in Advanced Societies. London: Sage. 
Erikson, Robert; Goldthorpe, John H. (1993), The Constant Flux: A Study of Class Mobility in Industrial Societies. Oxford: Clarendon Press.

Esping-Andersen, Gøsta (org.) (1993), Changing Classes: Stratification and Mobility in Post-Industrial Societies. London: Sage.

Estanque, Elísio (2000), Entre a fábrica e a comunidade: Subjectividade e práticas de classe no operariado de calçado. Porto: Afrontamento.

Estanque, Elísio; Mendes, José Manuel (1997), Classes e desigualdades sociais em Portugal: Um estudo comparativo. Porto: Afrontamento.

Estanque, Elísio; Nunes, João Arriscado (2002), "A Universidade perante a transformação social e as orientações dos estudantes: O caso da Universidade de Coimbra", Oficina do CES, 169, (http://www.ces.fe.uc.pt/publicacoes/oficina/oficina.php).

Fernandes, António Teixeira et al. (1998), Práticas e aspirações culturais: Os estudantes da cidade do Porto. Porto: Afrontamento / Câmara Municipal do Porto.

Fernandes, António Teixeira (org.) (2001), Estudantes do Ensino Superior no Porto: Representações e práticas culturais. Porto: Afrontamento.

Figueiredo, Alexandra Lemos; Silva, Catarina Lorga da; Ferreira, Vítor Sérgio (1999), Jovens em Portugal: Análise longitudinal de fontes estatísticas, 1960-1997. Oeiras: Celta.

Figueiredo, Eurico (1988), "Conflito de gerações: conflito de valores”, Coleç̧ão Portugal: Os Próximos 20 Anos. Lisboa: Fundação Calouste Gulbenkian.

Figueiredo, Eurico (2001), Valores e gerações: Anos 80 anos 90. Lisboa: ISPA.

Goldthorpe, John H. (org.); Llewellyn, Catriona; Payne, Clive (1980), Social Mobility and Class Structure in Modern Britain. Oxford: Clarendon Press.

Gonçalves, Carlos Manuel; Parente, Cristina; Veloso, Luísa (2001), "Licenciados em sociologia: ritmos e formas de transição ao trabalho", Sociologia: Revista da Faculdade de Letras do Porto, XI.

Grácio, Sérgio (1997), Dinâmicas da escolarização e das oportunidades individuais. Lisboa: EDUCA Formação.

Lewis, Suzan et al. (1999), Futuros em suspenso: Jovens europeus falam acerca da conciliação entre trabalho e família. Lisboa: Instituto Superior de Ciências do Trabalho e da Empresa.

Lopes, João Teixeira (1997), Tristes escolas: Práticas culturais estudantis no espaço escolar urbano. Porto: Afrontamento.

Machado, Fernando Luís (2002), Contrastes e continuidades: Migrações, etnicidade e integração dos guineenses em Portugal. Oeiras: Celta.

Machado, Fernando Luís; Ávila, Patrícia; Costa, António Firmino da (1995), "Origens sociais e estratificação dos cientistas”, in Jorge Correia Jesuíno (org.), A comunidade científica portuguesa nos finais do século XX. Oeiras: Celta, 109-133.

Machado, Fernando Luís; Costa, António Firmino da (1998), "Processos de uma modernidade inacabada”, in José Manuel Leite Viegas; António Firmino da Costa (orgs.), Portugal, que modernidade? Oeiras: Celta, 17-44. 
Machado, Fernando Luís; Costa, António Firmino da; Almeida, João Ferreira de (1989), "Identidades e orientações dos estudantes: Classes, convergências, especificidades", Revista Crítica de Ciências Sociais, 27/28, 189-209.

Mauritti, Rosário (2000), Estudantes universitários: Trajectórias sociais e expectativas de inserção profissional. Lisboa: ISCTE (diss. de mestrado).

Mauritti, Rosário (2002), "Padrões de vida dos estudantes universitários nos processos de transição para a vida adulta”, Sociologia, Problemas e Práticas, 39, 85-116.

Nunes, Adérito Sedas (2000a), “A população universitária portuguesa: uma análise preliminar”, in A. Sedas Nunes, Antologia sociológica. Lisboa: Instituto de Ciências Sociais da Universidade de Lisboa.

Nunes, Adérito Sedas (2000b), "O sistema universitário em Portugal: alguns mecanismos, efeitos e perspectivas do seu funcionamento”, in A. Sedas Nunes, Antologia sociológica. Lisboa: Instituto de Ciências Sociais da Universidade de Lisboa.

Pais, José Machado (1993), Culturas juvenis. Lisboa: INCM.

Pais, José Machado (1999), Consciência histórica e identidade: Os jovens portugueses num contexto europeu. Oeiras: Celta.

Pais, José Machado et al. (1998), Gerações e valores na sociedade portuguesa contemporânea. Lisboa: Instituto de Ciências Sociais da Universidade de Lisboa.

Parkin, Frank (1979), Marxism and Class Theory: A Bourgeois Critique. London: Tavistock Publications.

Pereira, Virgílio Borges (1999), Os vincados padrões do tecido social. Porto: Afrontamento.

Pereira, Virgílio Borges (2002), Modalidades de estilização de vida na cidade do Porto: Classes e culturas de classe das famílias portuenses. Porto: Faculdade de Letras da Universidade do Porto (diss. de doutoramento).

Pinto, José Madureira (1985), Estruturas sociais epráticas simbólico-ideológicas nos campos: Elementos de teoria e de pesquisa empírica. Porto: Afrontamento.

Pinto, José Madureira; Queiroz, Maria Cidália (1990), "Lugares de classe e contextos de aprendizagem social”, Cadernos de Ciências Sociais, 8/9.

Poulantzas, Nicos (1974), Les classes sociales dans le capitalisme aujourd'bui. Paris: Seuil.

Silva, Augusto Santos (1994), Tempos cruzados: Um estudo interpretativo da cultura popular. Porto: Afrontamento.

Smithson, Janet; Lewis, Suzan; Guerreiro, Maria das Dores (1998), "Percepções dos jovens sobre a insegurança no emprego e suas implicações no trabalho e na vida familiar”, Sociologia, Problemas e Práticas, 27, 97-113

Vester, Michael (2003), "Class and Culture in Germany”, Sociologia, Problemas e Práticas, 42, 25-64.

Wright, Erik Olin (1978), Class, Crisis and the State. London: Verso.

Wright, Erik Olin (1985), Classes, London: Verso.

Wright, Erik Olin (1997), Class Counts: Comparative Studies in Class Analysis. Cambridge: Cambridge UP. 